\title{
Study on Contact Response Between Underwater and Silt Collision of Titanium Alloy Cylindrical Pressure-Resistant Structure
}

\author{
Lin Wang, Shuaishuai Zhu, Xiaogang Qian
}

\begin{abstract}
Be aimed at the speciality and complexity of the submersible collision problem, based on the nonlinear finite element method and considering the influence of structural contact and friction during contact collision and the additional water quality of submerged underwater collision, A simulation model for the contact collision between cylindrical pressure-resistant structure and silt is established. The speed, acceleration, maximum stress/strain and impact depth of the pressure shell are analyzed by comparison of four working conditions. The results show that the nonlinear finite element method can accurately analyze the submerged contact collision process.
\end{abstract}

Index Terms - submersible, collision, silt, finite element analysis

\section{INTRODUCTION}

With the rapid development of the world economy today, energy shortages have become the most concerned economic factor by governments. Today, as the energy output of traditional oil producing areas is weakening, many countries have turned their eyes to the vast ocean. There are huge resources at the bottom of the ocean. With the development of modern civilization, people are speeding up the development of the ocean, from the offshore to the distant sea, from the shallow sea to the deep sea. As a powerful tool, the submersible plays an important role in the way of human beings to understand the ocean, develop the ocean, and protect the ocean. As the first operational deep-sea manned submersible in China, the "Jiao Long" came into being. According to Cui Weicheng, the chief designer of the "JiaoLong", once "JiaoLong" dived to the bottom of the sea, the agitation of the propeller stirred the mud at the bottom of the sea, the driver's line of sight was blocked, and the working arm was accidentally inserted into the mud, and to got it, it took a long time. Fortunately, there is no danger of getting out of this trouble, If can't pull it out or the machine is damaged during in this time, it will be a major disaster. At present, there are few studies on this aspect at home and abroad[1]. In this paper, the finite element analysis software ANSYS/LS-DYNA is used to investigate the response of

Lin Wang Doctor of Engineering, Professor, Postgraduate Tutor, Executive director of China Offshore Engineering Society of steel structures, Member of the Seventh Council of structural stability and fatigue branch of China Steel Structure Association. Member of the Structural Strength Group of the Specialized Committee of Ship Mechanics. China.

Shuaishuai Zhu Postgraduate of Naval Architecture and Ocean Engineering department of Jiangsu University of Science and Technology, China. +8618896658870

Xiaogang Qian Postgraduate of Naval Architecture and Ocean Engineering department of Jiangsu University of Science and Technology, China.+8613912206522 titanium alloy cylindrical pressure-resistant structure to underwater contact with sludge.

\section{CALCULATION PRINCIPLE OF SUBMERSIBLE COLLISION PROBLEM}

Due to the great similarity between the environment, structural form, load of the pressure-resistant structure and the ship or submarine, and the important role of the submarine in the national defense industry, the theoretical development of the pressure-resistant structure is relatively outdated. It generally adopt and draw on the relevant norms and theories of ships or submarines. Collision is a complex nonlinear transient response process. The structural members in the collision zone generally enter the plastic flow state rapidly across the elastic phase. Various forms of damage or failure such as bending, dent, tear, and break may occur during in this process [2].

\section{A. Research methods of collision}

From the perspective of ship collision research methods, there are mainly four kinds of ship collision research methods: experimental research method [3], statistical analysis method [4], numerical calculation method based on ship collision mechanics [5], finite element numerical simulation method [6]. The finite element numerical simulation method is adopted in this paper.

\section{B. Characteristics of submersible collision}

The structure of the submersible itself is quite different from that of the surface ship, and the wet surface to the shell area ratio is much larger than that of the surface ship. Therefore, the fluid-solid coupling during the collision process of the pressure-resistant structure is more significant, and the influence of hydrostatic pressure in the deep-water environment is not negligible [7].

a) Additional water quality

The additional water quality is mainly used to reflect the interaction between the hull and the fluid. Its size depends mainly on the profile characteristics of the collision ship, the collision history, etc. The accurate calculation is quite complicated and difficult. Therefore, the additional water quality of the advancing and retreating movement generally adopts the empirical formula [8]:

$$
X_{H}(t)=-m_{x x} \dot{u}
$$

Where: $X_{H}(t)$ is the hydrodynamic force acting on the hull; $\dot{u}$ is the acceleration of the hull. By comparing the experimental data and the results, the scholar Motora 
concluded that the additional water quality $m_{x x}$ of the advance and retreat movement is small compared with the hull mass $m$.

b) Mechanical properties of TC4 materials

The composition of titanium alloy TC4 material is Ti-6Al-4V, which belongs to $(\alpha+\beta)$ type titanium alloy. Its comprehensive mechanical and mechanical properties are relatively good, the strength is high, the corrosion resistance, the heat resistance is high, the toughness and weldability are good. Terefore,it is Widely used. Compared with marine steel, the titanium alloy with high strength and toughness is selected because the working depth of the submersible is very large.

\section{NUMERICAL SIMULATION OF CYLINDRICAL PRESSURE-RESISTANT STRUCTURE}

In this paper, the cylindrical pressure-resistant structure of a certain titanium alloy material is simulated by underwater large-scale finite element analysis software ANSYS/LS-DYNA, and the influence of attached water quality is considered. To get The response analysis results of pressure-resistant structure during the contact to sludge contact to zero velocity, the parameters such as stress, strain, collision force and energy change in the contact area are analyzed.

\section{A. Calculation model}

The model is built in the simulation software ANSYS as shown in Fig. 1.

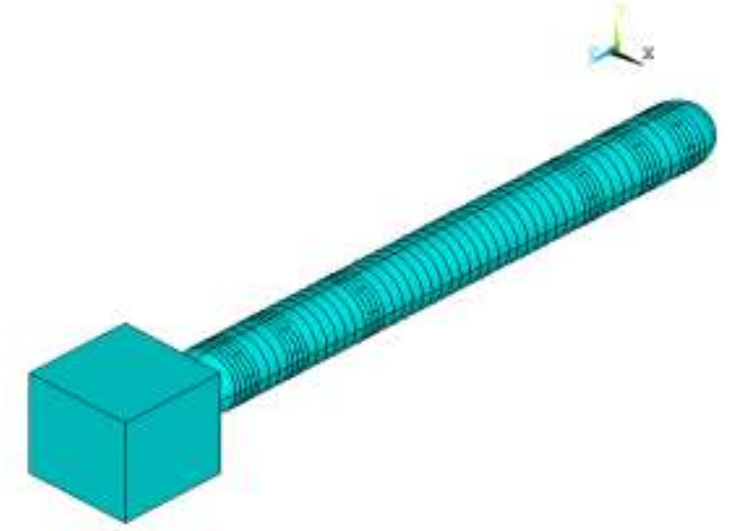

Fig.1. Pressure structure contact calculation model

Where: the sludge model is a cube of $4 \mathrm{~m} \times 4 \mathrm{~m} \times 4 \mathrm{~m}$; The cylindrical pressure-resistant structure's parameters are as follows in Tab.1.

Tab.1 Cylindrical pressure structure parameters

\begin{tabular}{cccccc}
\hline $\begin{array}{c}\text { Length } \\
\mathrm{L} / \mathrm{m}\end{array}$ & $\begin{array}{c}\text { Diameter } \\
\mathrm{D} / \mathrm{m}\end{array}$ & $\begin{array}{c}\text { spacing } \\
\text { of frame } \\
\mathrm{b} / \mathrm{m}\end{array}$ & $\begin{array}{c}\text { Shell } \\
\text { thickness } \\
\mathrm{a} / \mathrm{mm}\end{array}$ & $\begin{array}{c}\mathrm{T} \text { profile } \perp / \\
\mathrm{mm}\end{array}$ \\
\hline 数 & 21.6 & 2.3 & 0.4 & 17 & $\perp \frac{11 \times 160}{15 \times 100}$ \\
\hline 值 & & & & & \\
\hline
\end{tabular}

A. Cylindrical pressure-resistant structural material model and parameters

The cylindrical pressure-resistant structure is made of titanium alloy (TC4) material, the material model is *MAT_JOHNSON_COOK, and the material parameters are shown in the following table [9]:
Tab.2 Parameters of titanium alloy (TC4)

\begin{tabular}{ccccc}
\hline $\begin{array}{c}\text { DENS/ } \\
\mathrm{Kg} / \mathrm{m}^{3}\end{array}$ & $\begin{array}{c}\mathrm{EX} / \\
\mathrm{Pa}\end{array}$ & NUXY & $\begin{array}{c}T_{\text {meit }} / \\
\mathrm{K}\end{array}$ & $\begin{array}{c}\mathrm{A} / \\
\mathrm{Pa}\end{array}$ \\
\hline 4430 & $1.35 \mathrm{E} 11$ & 0.33 & 1878 & $1.06 \mathrm{E} 9$ \\
\hline \hline $\mathrm{B} / \mathrm{Pa}$ & $\mathrm{n}$ & $\mathrm{C}$ & $\mathrm{m}$ & $\mathrm{Ef} \mathrm{P1} \mathrm{SR}$ \\
\hline $1.09 \mathrm{E} 9$ & 0.884 & 0.0117 & 1.1 & $4 \mathrm{E}-4$ \\
\hline \hline$D_{1}$ & $D_{2}$ & $D_{a}$ & $D_{4}$ & $D_{5}$ \\
\hline-0.09 & 0.27 & 0.48 & 0.014 & 3.87 \\
\hline
\end{tabular}

\section{A. Material model and parameters of sludge}

In this paper, the soil model parameters are used to simulate the seabed sludge. The model used is *MAT_SOIL_AND_FOAM, and the material parameters are shown in the following table.

Tab.3 Parameters of silt materials

\begin{tabular}{cc|cc|cc}
\hline $\mathrm{R}_{0}$ & $1800 \mathrm{~kg} / \mathrm{m}^{3}$ & $\mathrm{EPS}_{2}$ & -0.104 & $\mathrm{P}_{2}$ & $2 \mathrm{E} 7 \mathrm{~Pa}$ \\
$\mathrm{G}$ & $6.385 \mathrm{E} 7 \mathrm{~Pa}$ & $\mathrm{EPS}_{3}$ & -0.161 & $\mathrm{P}_{3}$ & $4 \mathrm{E} 7 \mathrm{~Pa}$ \\
$\mathrm{BULK}$ & $3 \mathrm{E} 10 \mathrm{~Pa}$ & $\mathrm{EPS}_{4}$ & -0.192 & $\mathrm{P}_{4}$ & $6 \mathrm{E} 7 \mathrm{~Pa}$ \\
$\mathrm{~A}_{0}$ & $3.4 \mathrm{E} 9 \mathrm{~Pa}^{2}$ & $\mathrm{EPS}_{5}$ & -0.224 & $\mathrm{P}_{5}$ & $1.2 \mathrm{E} 8 \mathrm{~Pa}$ \\
$\mathrm{~A}_{1}$ & $7.033 \mathrm{E} 4 \mathrm{~Pa}$ & $\mathrm{EPS}_{6}$ & -0.246 & $\mathrm{P}_{6}$ & $2 \mathrm{E} 8 \mathrm{~Pa}$ \\
$\mathrm{~A}_{2}$ & 0.3 & $\mathrm{EPS}_{7}$ & -0.271 & $\mathrm{P}_{7}$ & $4 \mathrm{E} 8 \mathrm{~Pa}$ \\
$\mathrm{PC}$ & $-6.9 \mathrm{E} 3 \mathrm{~Pa}$ & $\mathrm{EPS}_{8}$ & -0.283 & $\mathrm{P}_{8}$ & $6 \mathrm{E} 8 \mathrm{~Pa}$ \\
$\mathrm{VCR}$ & 0 & $\mathrm{EPS}_{9}$ & -0.290 & $\mathrm{P}_{9}$ & $8 \mathrm{E} 8 \mathrm{~Pa}$ \\
$\mathrm{EPS}_{1}$ & 0 & $\mathrm{EPS}_{10}$ & -0.400 & $\mathrm{P}_{10}$ & $4.1 \mathrm{E} 9 \mathrm{~Pa}$ \\
\hline
\end{tabular}

\section{B. Introduction of calculation condition}

This paper mainly calculates four conditions:

Condition 1: cylindrical pressure resistant structure at $0 \mathrm{~m}$, with initial velocity $1.5 \mathrm{~m} / \mathrm{s}$ colliding with silt.

Condition 2: cylindrical pressure resistant structure at underwater $200 \mathrm{~m}$, with initial velocity $1.5 \mathrm{~m} / \mathrm{s}$ colliding with silt contact.

Condition 3: cylindrical pressure resistant structure at underwater $400 \mathrm{~m}$, with initial velocity $1.5 \mathrm{~m} / \mathrm{s}$ colliding with silt contact.

Condition 4: cylindrical pressure resistant structure at underwater $800 \mathrm{~m}$, with initial velocity $1.5 \mathrm{~m} / \mathrm{s}$ colliding with silt conta.

\section{ANALYSIS OF CALCULATION RESULTS}

\section{A. Analysis of collision force}

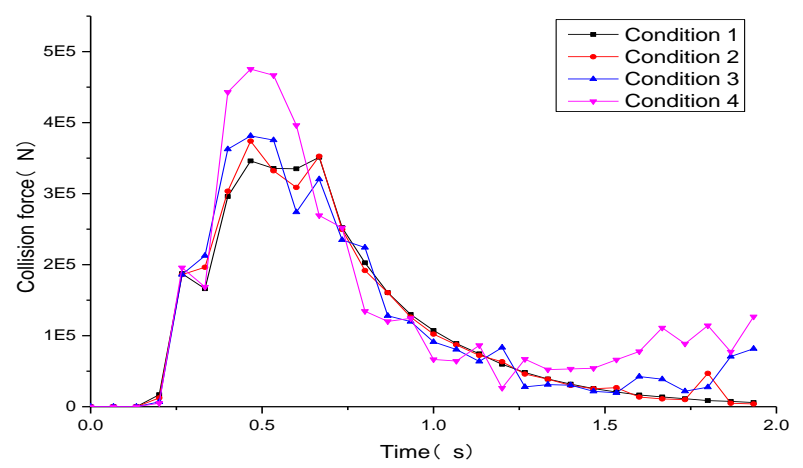

Fig. 2 Collision force curve under four working conditions

It can be seen from Fig. 2 that the contact collision occurs at time $($ time $=0.133 \mathrm{~s})$, and the collision force reaches the maximum value at time $=0.4668 \mathrm{~s}$, and the collision force 
gradually increases with the increase of water depth. The maximum collision force at $800 \mathrm{~m}$ under water is $4.75360 \mathrm{E} 5 \mathrm{~N}$. It shows that the increase of external pressure increases the value of maximum collision force of the cylindrical pressure-resistant structure, which increases the severity of the collision. As the water depth increases, the degree of danger in the event of a collision increases.

Analysis of maximum stress / strain results

Tab.4 Maximum stress/strain and its cells position

\begin{tabular}{l|ccc|ccc}
\hline & $\begin{array}{c}\text { Maximum } \\
\text { stress } \\
\text { /Pa }\end{array}$ & $\begin{array}{c}\text { Time } \\
\text { /s }\end{array}$ & $\begin{array}{c}\text { Location } \\
\text { of cell }\end{array}$ & $\begin{array}{c}\text { Maximum } \\
\text { strain }\end{array}$ & $\begin{array}{c}\text { Time } \\
/ \mathrm{s}\end{array}$ & $\begin{array}{c}\text { Location } \\
\text { of cell }\end{array}$ \\
\hline $\begin{array}{l}\text { Condition } \\
1\end{array}$ & $1.215 \mathrm{E} 8$ & 0.2 & $\# 4362$ & - & - & - \\
$\begin{array}{l}\text { Condition } \\
2\end{array}$ & $3.118 \mathrm{E} 8$ & 0.52 & $\# 4300$ & $1.607 \mathrm{E}-2$ & 1.8 & $\# 6839$ \\
$\begin{array}{l}\text { Condition } \\
3\end{array}$ & $5.453 \mathrm{E} 8$ & 1.2 & $\# 6839$ & $5.789 \mathrm{E}-2$ & 1.9 & $\# 4328$ \\
$\begin{array}{l}\text { Condition } \\
4\end{array}$ & $1.265 \mathrm{E} 9$ & 1.6 & $\# 4336$ & $1.152 \mathrm{E}-1$ & 2 & $\# 4328$ \\
\hline
\end{tabular}

Through the analysis of Tab.4, it can be concluded that the stress and strain of the pressure-resistant structure increase with the increase of water depth. The area where the maximum stress and strain appear is the area where the column pressure structure is in contact with the mud. The maximum plastic strain occurs at a certain lag time compared to the time when the maximum stress occurs.

\section{A. Analysis of collision speed}

Take the element \#520 on the middle shell of the cylindrical pressure-resistant structure as the research object, and get the fig. 3:

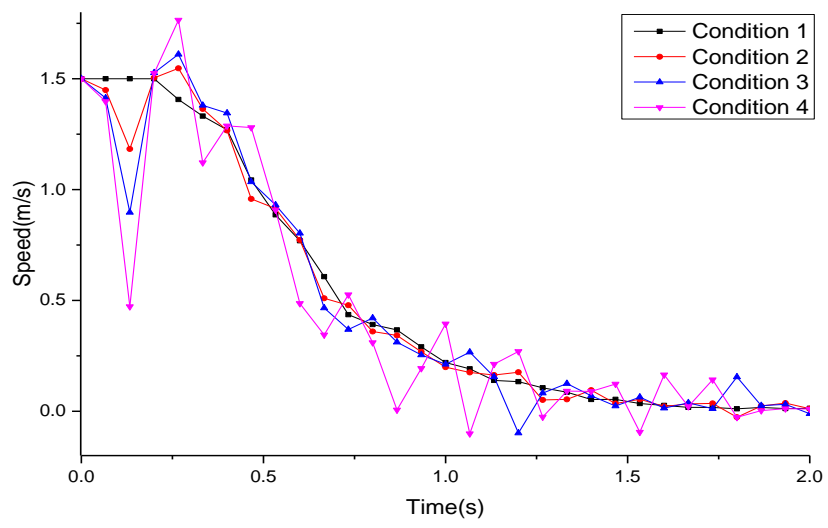

fig.3 elem\#520 Speed curve

Submersible collision belongs to low-speed collision. The variable impact zone structure and the existence of water in underwater collision play a similar role as "buffer" in the process of collision impulse transmission. The lag of impulse transmission and the huge mass inertia of the collision submarine inevitably lead to the collision damage deformation lagging behind the collision motion of the submarine.

From the analysis of Fig.3, it can be concluded that the velocity of the cylinder pressure-resistant structure increases slightly with the increase of water depth before the cylinder pressure-resistant structure is in contact with the silt under water (working condition 2-4). After contacting the surface of the silt, because of the hysteresis of the underwater impulse , the cylinder 'breaks through' the mud surface at the speed of over $1.5 \mathrm{~m} / \mathrm{s}$ with the increase of water depth; the velocity is zero after $1.75 \mathrm{~s}$ in all four working conditions, that is, the cylinder compressive structure decelerates to complete static under the mud damping. And with the increase of water depth, the less time the speed reaches 0 .

\section{B. Analysis of collision depth}

The element \#520 on the middle casing of the cylindrical pressure-resistant structure was selected as the research object. The displacement of the cylindrical pressure-resistant structure in the Z-axis direction is shown in Fig. 4:

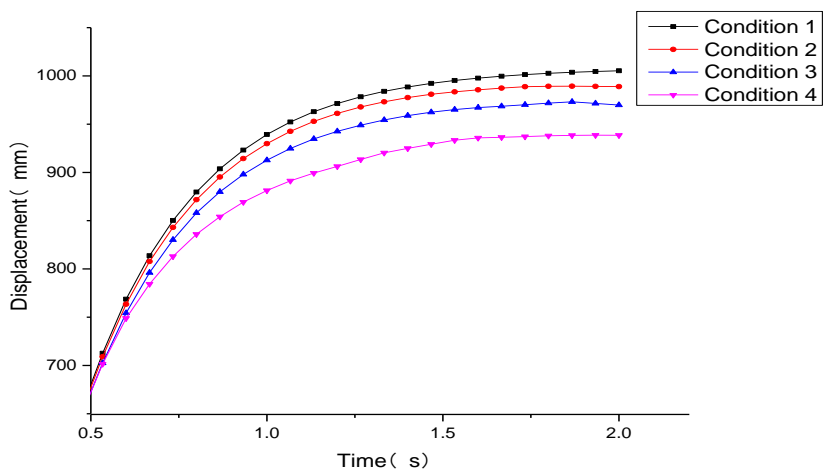

Fig.4 Displacement comparison chart under various working conditions

Cylinder pressure-resistant structure impact analysis: The displacement of the cylindrical pressure-resistant structure in $2 \mathrm{~s}$ is shown in Fig.4. As the water depth increases, the collision depth becomes smaller. The depth of the water is $905 \mathrm{~mm}$, and the depth of the underwater $800 \mathrm{~m}$ is $838.5 \mathrm{~mm}$. The underwater $800 \mathrm{~m}$ collision depth is smaller than the collision depth of the water surface at $66.5 \mathrm{~mm}$.

C. Energy analysis

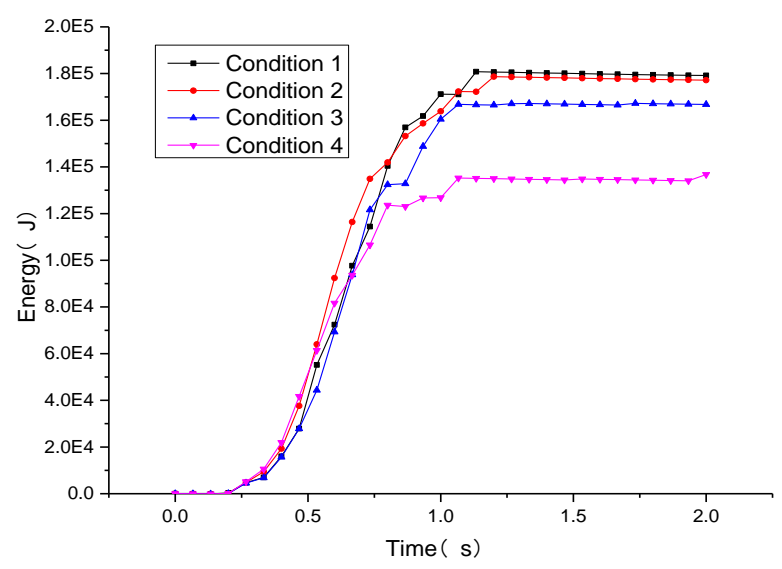

Fig. 5 Variation of sludge energy under four conditions When the collision with the sludge occurs on the water surface, the energy of the sludge increases the most. As the water depth increases, the amount of sludge energy increases. When the water depth is increased to $800 \mathrm{~m}$, the sludge energy increases the least, about $1.36 \mathrm{E} 5 \mathrm{~J}$.

\section{Acceleration analysis}

The evaluation of the acceleration mainly selects the collision contact area, that is, the node \#4441 at the head, the node \#691 at the middle of the cylindrical pressure-resistant shell, and the tail end node $\# 3030$ of the cylindrical pressure-resistant shell as the evaluation node. 


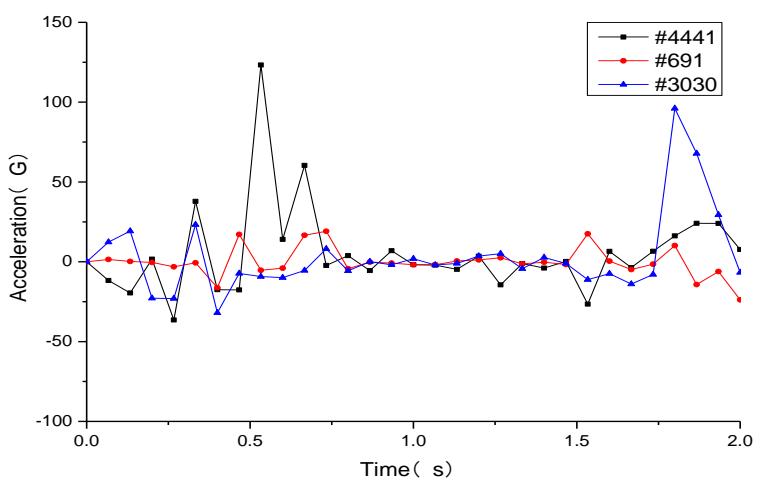

(a) Condition 1 acceleration-time curve

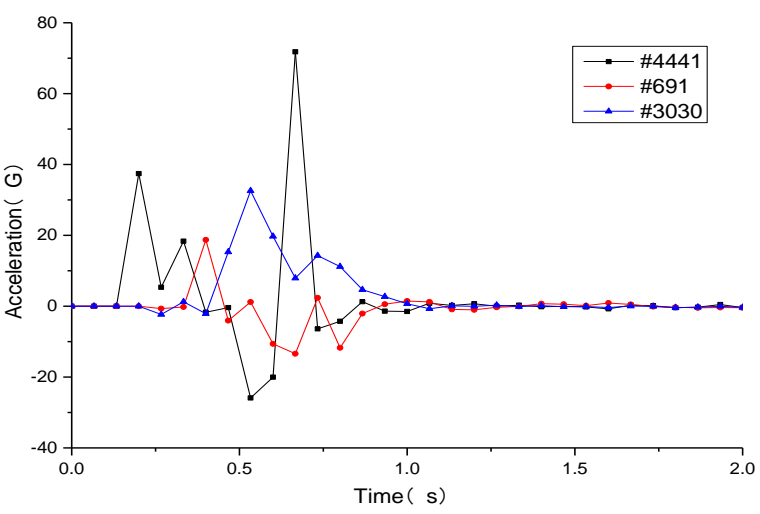

(b) Condition 2 acceleration-time curve

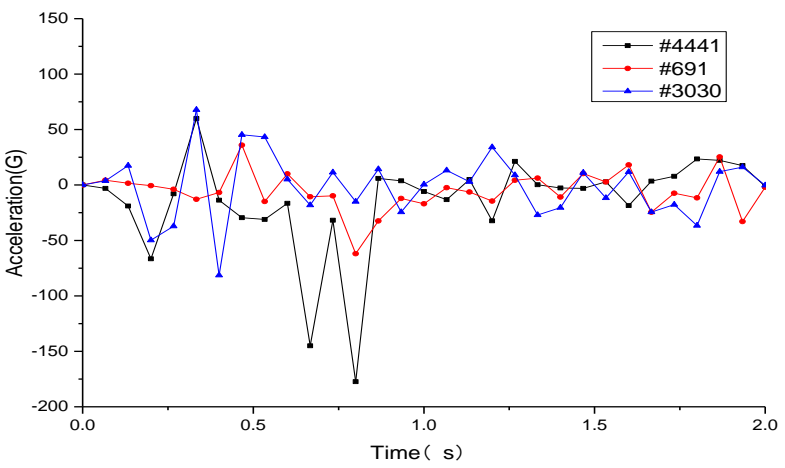

(c) Condition 3 acceleration-time curve

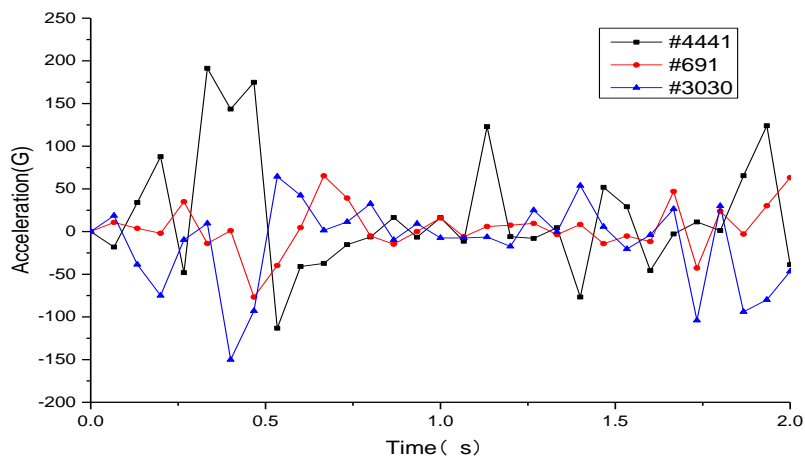

(d) Condition 4 acceleration-time curve

Fig.6 Acceleration time curve under four working conditions

Before the cylindrical pressure-resistant shell contacts the sludge, the speed will change due to the water pressure. With the increase of water depth, the acceleration shows a trend of 'turbulence', and the maximum acceleration increases with the increase of water depth. The maximum acceleration at $800 \mathrm{~m}$ underwater is $191 \mathrm{G}$.

\section{CONCLUSION}

Based on ANSYS/LS-DYNA, this paper studies the problem of underwater cylindrical pressure-resistant structure contact collision with mud. The simulation results of four different working conditions are compared and analyzed. The main conclusions are as follows:

1) The underwater collision of cylindrical pressure-resistant structure is a complex transient response process. The nonlinear finite element software ANSYS/LS-DYNA can be used for numerical simulation. In the contact collision with the sludge, the maximum stress/strain received has a very obvious locality, and the overall deformation of the collision region is small and negligible.

2) The rigid body motion of the submersible due to the collision has a certain hysteresis with respect to the collision area. The main response is the maximum stress/strain, velocity and the "transferability" of acceleration from the head to the tail. This hysteresis gradually increases with increasing water depth.

3) The impact of the impact parameters on the collision characteristics of the submersible pressure structure is multi-faceted.Different collision parameters will lead to different structural motion responses.

4) When considering the pressure of deep water environment, the crashworthiness of the cylindrical pressure-resistant structural shell will be much lower than that of the load environment without considering the hydrostatic pressure.

\section{REFERENCES}

[1]MONTFORT C,,CHAUVET M. ANALYSIS OF THE COLLISION OF A SUBMARINE[C].//68TH SHOCK AND VIBRATION SYMPOSIUM.1997.

[2]YU Hao, LI Chenfeng, REN Huilong, LIN Yi. Collision dynamic response research of a submersible[J]. Harbin Engineering University, 2011,32(12):1527-1533.

[3]JONES N. A literature survey on the collision and groundingprotection of ships[R].Ship Structure Committee Report,1979,No.SSC-283.

[4]JONES N.JOURI W S. A study of plate tearing for shipcollision and grounding damage[J].Journal of Ship Re-search,1987,31(4):253-268.

[5]McDERMOTTJ F,KLINE R GJJONES E Tanker structural analysis for minor collisions[J]. Transactions of the ASME,1974,82;382-414.

[6]DONNER R,BESINER F,SOURNE L.Numerical simulation of ship-submarine collision $[\mathrm{C}] / 8^{\text {th }}$ International Symposium on Practial Design of Ship and Other Floating Structures. Shanghai Chine,2001:1309-1314.

[7]Mei Zhiyuan. Numerical analysis based on MSC/Dytran collision strength of submarine structure[J].Computer.Aided.Engeering,2006,15(suppl):71-74.

[8] Shen Weiwei. Research on Semi-submersible Offshore Platform Structural Response Under the Supply Ship Collision[D]. Jiangsu University of Science and Technology,2017.

[9] XI Xulong, LIU Xiaochuan, WANG Jizhen, BAI Chunyu. High Velocity Impact Failure and Ballistic Performance of TC4 Plate[J]. Science Technology and Engineering,2017,17(11):1-8.

Lin Wang Doctor of Engineering, Professor, Postgraduate Tutor, Executive director of China Offshore Engineering Society of steel structures, Member of the Seventh Council of structural stability and fatigue branch of China Steel Structure Association. Member of the Structural Strength Group of the Specialized Committee of Ship Mechanics. China.

Shuaishuai Zhu Postgraduate of Naval Architecture and Ocean Engineering department of Jiangsu University of Science and Technology, China.+8618896658870

Xiaogang Qian Postgraduate of Naval Architecture and Ocean Engineering department of Jiangsu University of Science and Technology, China.+8613912206522 